\title{
Persuasion in ambient intelligence
}

\author{
Maurits Clemens Kaptein • Panos Markopoulos • \\ Boris de Ruyter $\cdot$ Emile Aarts
}

Received: 15 May 2009/ Accepted: 30 September 2009/Published online: 4 December 2009

(C) The Author(s) 2009. This article is published with open access at Springerlink.com

\begin{abstract}
Although the field of persuasive technologies has lately attracted a lot of attention, only recently the notion of ambient persuasive technologies was introduced. Ambient persuasive technologies can be integrated into every aspect of life, and as such have greater persuasive power than the traditional box like machines. This article discusses ambient persuasion and poses a model that structures the knowledge from social sciences on persuasion, attitude change, and behavior change. Using this model the challenges of ambient persuasive technologies to fulfill its persuasive promises are identified. From the ambient persuasion model it is clear that ambient persuasive technologies can go beyond traditional persuasive technologies by being context and situational aware, by interpreting individual differences between users, and by being a social actor in their own right.
\end{abstract}

Keywords Persuasion - Ambient intelligence ·

Attitude change $\cdot$ Behavioral change

\section{Introduction}

Attitude change and behavioral change are heavily researched in social sciences. Its knowledge stems from domains coined attitude change, learning, conditioning, heuristics, persuasive cues and many others. Given the

M. C. Kaptein $(\bowtie) \cdot$ P. Markopoulos

Industrial Design, Eindhoven University of Technology,

Eindhoven, The Netherlands

e-mail: m.c.kaptein@tue.nl

B. de Ruyter - E. Aarts

Philips Research, Eindhoven, The Netherlands diversity of the work in different areas, and its differences in practical use for system design, we present a model to structure the most relevant works in persuasion for system design. We adopt the term persuasion in a very broad sense and identify a persuasive system as any system successfully and intentionally designed to influence attitudes or behaviors of its users. This is in line with the definition posed by O'Keefe (2002) who defines persuasion as a successful intentional effort of influencing another's mental state.

Fogg (2003) brought persuasion into computing with his valuable work on persuasive technologies. We add to his achievements by focusing more heavily on the psychological underpinnings of attitudes and behaviors, and by extending the work to the ambient intelligence (AmI) scenario, thus stepping away from the traditional boxed computer. Aarts et al. (2007) combined the notions of ambient intelligent systems-systems that build on the large scale integration of electronic devices and the ubiquitous availability of digital information - and persuasive technologies; systems aimed at changing users attitudes or behaviors (Fogg 2003).

In an AmI world, massively distributed devices operate collectively while embedded in the environment using information and intelligence that is hidden in the interconnection network (Aarts and Ruyter 2009). Furthermore, system behavior can be adapted to user behavior since behavioral data is, in theory, freely available and shared between all parts of the system, or even between systems. The AmI scenario as such provides numerous opportunities for persuasion which are out of reach for their "boxed" counterparts. This article provides an overview of persuasive strategies which could be utilized by these ambient persuasive systems. The AmI paradigm can be regarded as the newest marker on a scale ranging from the traditional 
computer, to mobile devices, and trough pervasive computing. While pervasive computing already focuses on distributed systems, the AmI paradigm aims at taking the embedding of devices one step further by involving the entire environment (Aarts and Ruyter 2009).

We hope this article accelerates the development of ambient persuasive systems by identifying the major opportunities. This article should inspire the design of experiments to further advance the implementation of social science knowledge on persuasion into system design. Furthermore, we hope that this discussion initiates the development of complex systems; systems which incorporate the many moderating factors found in studies of attitude and behavioral change. Currently the majority of persuasive technologies leverage merely one or two persuasive tricks. Even though the effectiveness of such tricks for persuasive technologies has been shown (Fogg 2003), it is known from the studies of attitude change that straightforward tricks can have counterintuitive effects in specific contexts, or on specific individuals (Petty and Cacioppo 1986). In this article we present a model which incorporates the moderating variables that have been identified in different fields and as such provide guidelines for more effective persuasive systems.

We present an overview of the social science findings on attitude and behavioral change and summarize these in a model for ambient persuasion. The majority of persuasive strategies described in our ambient persuasion model originate from social sciences literature on human to human persuasion. However, given known similarities between human responses to humans and human responses to computers (Reeves and Nass 1996; Nass and Moon 2000) we believe that the social science literature can aid the design of ambient persuasive systems. In this paper we structure this knowledge and provide guidelines for design derived from this body of literature. We discuss each part of the model in detail. The article ends with identification of three major challenges for the AmI field to fulfill its opportunities in incorporating persuasion. The promises are vast, but they still need to be met.

\section{An ambient persuasion model}

In the next section we discuss the ambient persuasion model which structures the social sciences knowledge of persuasion into accessible and usable subsections for the development of ambient persuasive systems.

The ambient persuasion model (Fig. 1) is structured around two axes: (1) A classical representation of a persuasive message or cue delivered from a source to a receiver (left-right) and (2) the gradual change process

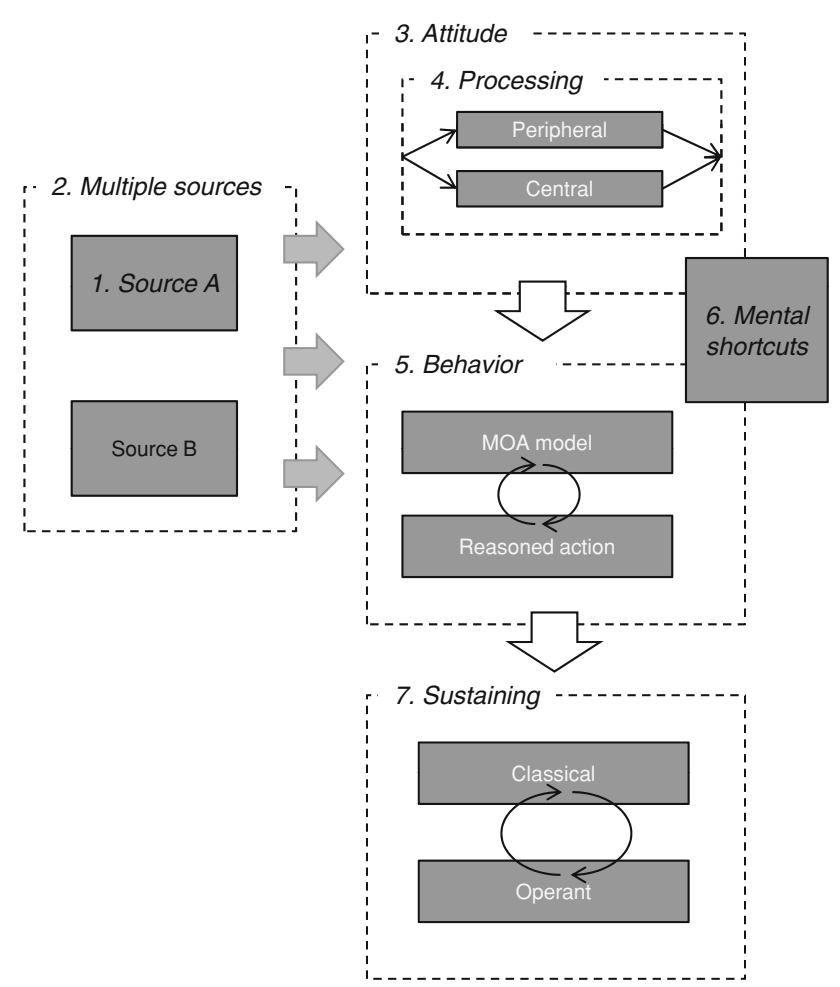

Fig. 1 The ambient persuasion model with from left to right the source to receiver effects and from top to bottom the distinctions between attitude change, behavioral change, and long term sustained behavior

from initial attitudes to sustaining long term behavior (topbottom).

\subsection{From source to receiver-the horizontal axis}

The first axis, pointing from the source of a persuasive request to the receiver, represents a very classical attitude change model (Petty et al. 1997); one person-the source-asks a request or speaks an opinion, and the other person-the receiver-changes attitude or behavior. We incorporate this classical paradigm into our model because of the valuable insights it delivers for the active role ambient persuasive systems could take as a source in this process. Furthermore, we extend this classical paradigm by discussing the implications of multiple sources of persuasive requests; the embedding of a receiver in his or her social environment.

\subsection{From attitude to long-term sustained behavior-the vertical axis}

The second axis, from initial attitude towards long-term behavior, has previously been identified by Aarts et al. (2007). Commonly people first form an opinion about a topic, for example one decides that going to the gym once a 
week is healthy and thus a good habit. A persuasive system could give cues or arguments to adopt this attitude. From this initial attitude people become motivated to perform the behavior. Here an ambient persuasive system could function as a tool (Fogg 2003) by making this behavior easier to perform. Finally, once the behavior has been performed it is necessary to sustain the adopted behavior, for example by punishment or reward. Structured around this axis we discuss the major views on attitude and behavior change, the use of mental shortcuts, the different routes of information processing that people use, and the majority views on sustaining behaviors.

\subsection{Overview of this article}

The numbered and italicized concepts in the model represent the clusters of research we use to structure the body of social sciences literature on attitude and behavioral change. This is the order in which we discuss the different concepts in this article. We begin by discussing the source (1), the originator of the persuasive request, which in our case is the ambient persuasive system. We describe how source characteristics influence the receiver's susceptibility to its persuasive cues. Second, we describe the effects of multiple sources (2), e.g. being surrounded by multiple persuaders. The request of a single source cannot be decoupled from its surrounding. Characteristics of multiple sources influence individuals compliance to persuasion.

After discussing the source characteristics the sequence of attitude change, behavioral change and methods to sustain the behavioral change is assessed. We start with attitudes and theories of attitude formation (3). To properly discuss attitude change we have to incorporate different processing theories (4) which describe how individuals process information and derive a decision. The hypothesized structure of attitudes in social sciences has an impact on the possible mechanisms to change attitudes and is thus important to incorporate in our model. The two information processing routes-the central and the peripheral routedetermine how people will respond to different cues and are thus of special importance for ambient context and situational aware persuasive systems.

From attitudes we proceed to discussing behavior (5), and focus on the onset of behavior; Why are certain behaviors preferred above competing behaviors, and which behavior is most likely to occur? We discuss theories of competing behaviors and their probability-theories which could be incorporated to create ambient persuasive systems which deliver the right message at the right time. The formation of behaviors and attitudes is frequently not consciously elaborated, it is also determined by heuristics and mental shortcuts (6) that individuals use, we discuss the most common shortcuts and their possible implementations.
These mental shortcuts can instantly lead to attitudinal or behavioral change, especially in situations of low information processing ability or low motivation to process the request of the receiver.

Next to the onset of behaviors we also discuss the research on sustaining (7) behavior, with an emphasis on conditioning. This overview section describes how ambient persuasive systems could incorporate strategies to strengthen and maintain behaviors exhibited by users. The last sections of this article describes the challenges for designers to incorporate persuasion into ambient systems to fulfill its promises. In the following sections we will discuss each of the numbered elements of the model in more detail.

\section{A single source}

The world famous Milgram (1963) experiment showed convincingly in 1963 the devastating effects source characteristics could have on a behavioral request of subjects in an experiment. Up to $65 \%$ of the subjects in his experiment allegedly went as far as killing another subject for not properly recalling a set of memorized words. One of the leading explanations for the accounted effect is the authority-expert credibility — of the source; the professor making the request.

Next to authority several other source characteristics influence the effectiveness of a persuasive request. Heavily researched of these (single) source effects are perceived friendliness, perceived similarity, mimicry, and reciprocity. The conclusions are summed below:

- A greater perceived legitimate authority increases compliance to a persuasive request.

- Sources that are considered friendly, or are liked by the receiver, increase compliance to their requests.

- A greater perceived similarity of the source of the request and the receiver increases compliance.

- Mimicry-similarities in behavior-by a source relative to a receiver increase compliance.

- People are inclined to return-reciprocate-a favor.

- Repetition-multiple exposures to the same source over time-increases compliance.

The summed conclusions show that source characteristics can make a big impact on the compliance to a persuasive request.

The Milgram experiment showed that authority-as shown by title of the researcher, the location of the research and the attributes the researcher was carrying (Milgram 1974; Cialdini 2001)—greatly effects compliance. Subsequent research has shown that the positive effect on compliance is highest when the authority figure is 
perceived credible (Millers et al. 1995), and when the receiver is limited in his or her elaboration efforts of the provided argument (Petty and Cacioppo 1986; Millers et al. 1995). Similar arguments have been shown to be effective in a virtual setting (Slater et al. 2006). Authority, or expert credibility, can be used in ambient systems when the system is an active actor itself and increase the compliance to the system. Incredible, or illegitimate authority can however lead to decreased compliance, especially when the receiver heavily elaborates on the content of the request.

Friendliness, or the perceived friendliness of the source, also effects the compliance of a receiver. People are inclined to listen to friends (Cialdini and Goldstein 2004), or more general inclined to comply to people they like (Cialdini 2001, 2004). This finding influences the development of ambient persuasive systems as it signals the importance of the social actor role of the system. It has been shown previously that simple social cues such as praise can increase the perceived friendliness of a virtual source (Kaptein et al. 2009).

Similarity between source and receiver leads to greater compliance (Festinger 1954). This similarity can occur at multiple levels. For example, it has been shown that people are more inclined to follow a request made by an unfamiliar person whose name is similar to their own than to a person with a different name (Burger et al. 2004). Furthermore, characteristics such as country of origin, religious affiliation, and educational background all influence compliance to a persuasive request; greater similarity increases compliance (Shultz 1999; Murray et al. 1984). An interesting development is the empirical evidence for greater liking and a more positive opinion of people with whom one momentarily shares an experience (Pinel et al. 2006). Perceived similarity through shared experiences is likely to have an effect on compliance, and shared experiences can be designed into ambient persuasive systems.

Mimicry has a very profound effect on the compliance to a persuasive request (Chartrand and Bargh 1999; Chartrand et al. 2005). Not only compliance is effected; the perceived friendliness, and the perceived intelligence are also influenced by mimicry. Mimicry refers to the (unconscious) copying of others behaviors. Mostly this is displayed trough body posture, facial expression or other non-verbal cues (Chartrand and Bargh 1999). However, verbal mimicry, both in prosody as well as in content has been shown to influence the perception of the receiver. Numerous implementations for mimicry in persuasive systems can be thought of and designed to test whether this principle holds within the ambient persuasion paradigm. First steps have been made in human to computer interaction in which it was shown that mimicry of typing speed by a chat robot positively influences people's opinion about the robot (Kaptein et al. 2009). Thus, even simple implementations of mimicry seem to influence the perception of the source, and as such can influence compliance.

People are inclined - or actually, people go through a great deal of effort-to pay back a favor (Cialdini 2004). This source characteristic is exceptionally strong, and seems to work even when it is truly unbeneficial for the receiver. When a receiver is in depth to the source, he or she will comply with persuasive requests to even out this discrepancy. The strategy of reciprocation-the foundation of the tit-for-tat strategy, which is the most favorable algorithm to win social dilemma games (Komorita et al. 1991) - seems rational. However, it has been shown that people even reciprocate to favors they had never asked for (Cialdini 2004; James and Bolstein 1992). Reciprocity, both in its rational and effective sense of reciprocating favors, as well as in its more deceptive sense, reciprocating unasked-for favors, can be utilized by ambient persuasive systems.

A final persuasion principle which we want to discuss in the context of a single source is the effect of reoccurring requests by a source. Repetition in persuasive requests increases compliance (Latane et al. 1995). The additive effect decreases as the number of repetitions increases but simple initial repetition of a request can greatly enhance the compliance.

Given these clear source effects we believe that for ambient systems to be persuasive designers should consider the role of the system as a persuasive source, and thus as an actor itself. When the ambient system functions as a social actor in the perception of the user, source characteristics can be utilized to increase compliance. Here a clear shift from purely functional system intelligence to emotional system intelligence is promoted (Aarts and Ruyter 2009), since notions like friendship and perceived similarity regard to social aspects of the system. These social behaviors, when properly displayed by a system, will first of all increase the bond between the system as actor and its users. More importantly, this created bond can be used to utilize source characteristics and increase compliance.

\section{Multiple sources}

Next to the influence of the perception of the receiver of a single source making a persuasive request, a number of multiple source effects exist. These effects are distinct form single source effects. Research in the area of multiple sources acknowledges that the compliance of an individual to a persuasive request is not merely determined by the current interaction between the source and the receiver, but also by previous interactions with others, interactions with the same source, and the number of repetitions. Thus, ones 
attitude or behaviors are dependent upon the social environment in which one lives. We briefly sum the main findings:

- Social proof is a powerful persuader. In uncertainty people look at the behavior and attitudes of others to determine their own.

- The number of people in reference group (for example in cases of social proof) or the absolute number of sources making a request influences compliance. More sources with a similar cue lead to higher compliance.

- Immediacy leads to compliance-people comply with those that are close or intimate to them.

- People generally seek consensus. People generally tend to minimize stress and conflict arising from competing opinions or behaviors.

First, social proof (Cialdini 2001) heavily influences attitudes and behaviors in a multitude of situations. The most striking example of social proof is the so-called bystander effect (Latane and Darley 1968): when an accident or attack happens on the street most people refrain from helping the victim. This is especially true when the incident occurs in a busy area where lots of people are around (Latane and Nida 1981). The explanation for this effect is that people, when confronted with an uncertain or unfamiliar situation, look at others to see what they should do. In the case of the incident on the street this results in each and everyone looking around to the others to see what they should to, and simultaneously noticing that they are doing the right thing; looking around to see what you should do seems to be what everyone else does. Social proof, and thus the cue that others behave in a certain manner or have a certain attitude can be used by ambient persuasive systems when the system is a tool (Fogg 2003) and shows you what others do. However, when the system is an actor-for which an argument was made in the preceding section—system behavior or attitude in itself could function as social proof. Systems could express attitudes or behaviors, and through social proof stimulate these same attitudes and behaviors by their users.

The next two findings-people are influenced by the number of people that make a request, and people listen to those close to them, are discussed together in the Dynamic Social Impact Theory (Latane 1996; Latane and Bourgeois 1996). Latane was one of the first and most influential to place persuasion and attitude formation in a dynamic social system, instead of relying merely on a dyadic source receiver relationship. The core of dynamic social impact theory is that the attitude one possesses towards a topic, for example your political affiliation, is a function of the strength of the arguments made in favor or opposing the attitude, the number of people expressing the attitude, and your immediacy to these people. Practically this means that your attitude towards republicans is a weighted average of all of the opinions you have ever heard from others. The weighting happens based on the closeness of others to you. The surprising finding of this theory is that if indeed attitudes are defined by this function it would mean, as shown by computer simulation, that groups of close people with similar attitudes should arise in a society, and that these groups should have similar attitudes on unrelated topics (Nowak et al. 1990). Furthermore, this social working of attitude formation ensures stable minority attitudes to be formed over time (Latane 1996).

The Dynamic Social Impact theory and its findings state that the number of people expressing an attitude and the immediacy of these people to the receiver influences the final attitude of the receiver can be used in persuasive systems. The immediacy statement provides another argument for building a close relationship between the ambient persuasive system and the user, and as such for an active social role of the system. The number of people statement shows how ambient persuasive systems can increase compliance by depicting the number of others currently performing the target behavior or holding the target opinion. This persuasive behavior of systems is currently in use in recommender systems and collaborative filtering systems and has proven its use in settings preceding the ambient persuasion paradigm. However, ambient systems could incorporate a number of measures which are out of reach to their boxed-like or mobile counterparts. Also, an ambient persuasive systems could leverage the power of the number of sources by acting as multiple actors. The system could depict multiple actors, specialized for different tasks, which work cooperatively in their interaction with the user.

Overall, the theory shows a promising focus on the social origins of attitudes and opinions. This social structure can be incorporated into a persuasive computing scenario. Social awareness of ambient persuasive systems could take the dynamic social properties of attitude formation into account.

Finally, another frequently researched multiple source effect is peoples innate motivation to seek consensus. People tend to agree with the people surrounding them. The consensus principle is clearly related to social proof but occurs also in situations in which people are not in uncertainty. An influential study by Ajzen and Fishbein (Asch 1955) has shown that respondents will adapt their judgment of the length of a line drawn on paper to the majority opinion of a group, even when this majority view is clearly wrong. This strive for consensus seems to be motivated by people's tendency to reduce stress, and can be used as a powerful persuader to change both attitudes as well as behavior. Persuasive systems could facilitate in the communication with others and encourage consensus. 
Systems which are a social actor by themselves could use the consensus principle to persuade users.

\section{The formation of attitudes}

We have discussed what the effects of one or multiple sources are on the compliance to a persuasive request. In this discussion we hardly distinguished between attitudes and behaviors; the second axis of the model. The following sections will deal with this second axis-the gradual process of changing attitudes, to changing behaviors, to sustaining the target behavior. In this first section on the second axis of our model we will discuss some of the theoretical views on what attitudes are, and how these impact the act of persuasion.

Attitudes have been defined in a variety of ways, but at the core is the notion of evaluation: Attitudes are viewed as a summary of evaluations of objects (thoughts, ideas, products, behaviors etc.) along a dimension ranging from positive to negative (Petty et al. 1994, 1997). Most general models explaining behavior start with a positive attitude and/or motivation towards a behavior before the actual exhibiting of behavior.

Research into the bases of attitudes has found several important notions for ambient persuasive systems. The main results can be summarized as follows:

- Mental accessibility of an attitude influences the strength of the attitude.

- Ambivalent attitudes - attitudes based on inconsistent information-are more easily changed.

- Mood, affect and cognition interact in forming attitudes.

- There seem to be individual (genetic) differences in attitude towards objects.

The strength of an object-evaluation association-e.g. the ease with which an evaluation of an object can be retrieved from memory-influences the final evaluation of the object (Fazio 1993; Bargh et al. 1996). Research has for example shown that a failure to recall a specified number of positive evaluations relating to an object decreases the final evaluation (Fazio 1995). For example, if a BMW fanatic is asked to name ten advantages of a BMW over a Mercedes, which is a challenging task, one observes a decrease in the overall evaluation of the BMW (Tybout et al. 2005). This decrease is present only when ten advantages are asked for, and is not present when three advantages are asked for. As such, the ease of retrieval of arguments of the object evaluation influences the evaluation itself. Moreover, even repetition of single arguments influences the final evaluation of an object - attitudes that are easily retrieved are commonly stronger e.g. more positive or more negative. Both of these notions of the structural base of attitudes as retrievals of object evaluations can be used in the design of ambient systems by aiding the retrieval of arguments.

Next to the accessibility of an attitude, the object evaluation is influenced by the ambivalence of the attitude. The ambivalence of an attitude is the extent to which the attitude is based on consistent information. This literature sees the final positive or negative evaluation of an object as a result of several negative and positive evaluations of aspects of the object (Cacioppo and Berntson 1994; Breckler 1994). Interesting from this perspective is that even though a final evaluation of an object might be strongly positive, the ease with which this evaluation can be changed depends not only on the strength-generally it is assumed that strong attitudes are less easily changed (Thompson et al. 1995) — but also on the ambivalence of the base of the attitude: The more pro and cons the attitude was based on, the more compliance with a counter attitudinal requests increases (Leippe and Eisenstadt 1994). As such, not merely the presenting of arguments in one specific direction, but also the sheer number of presented arguments might help in shaping an attitude.

Given the interpretation of attitudes as a summary of evaluations not only the accessibility of these evaluations or the ambivalence of these evaluations changes the end result. Research has shown that there is a distinction between attitudes having an affective base, and those having a cognitive base, and that this origin of attitudes influences how attitudes can be changed. Practically this distinction shows that attitudes towards some topics are more easily changed using affective - emotional-arguments, while some benefit from cognitive-fact-based arguments (Petty et al. 1997). This distinction is of importance for ambient persuasive systems since an attitude with an emotional base not easily changed by cognitive arguments and vice versa. Thus, assessment of the nature of current attitudes of users should impact the strategies adopted by a system to increase compliance.

A fourth focus of previous research is on the individual differences between people in their attitude formations and their sustaining of attitudes. The heated debate here concerns whether attitudes towards specific objects are not only influenced by experience but also by genetics (Lykken et al. 1993). While individual differences most definitely mediate how attributes are formed through experience, see for example the discussion of the need for cognition in Sect. 6, there are strong indications that there are genetic differences in attitudes (Tesser 1993). While the explanations for genetic differences in specific attitudes or attitude formation are brief and speculative (Petty et al. 1997) these could be highly interesting for the ambient persuasion domain and emphasize an importance for adaptive systems. 
Overall the structural basis of attitudes, being a summative evaluation of all possible validations of an attitude object influences the strategies which should be incorporated by ambient persuasive systems to increase compliance. The next section discusses how individual information processing leads to changes in attitudes or object evaluations.

\section{Information processing}

During our discussion of source effects we already touched upon the moderating effect of message elaboration on the effectiveness of authority as a cue to increase compliance. Mediating effects like these have been found in abundance in the attitude and behavioral change literature (Olson and Zanna 1993; Petty et al. 1997). Generally these effects seem confusing; the strong effect of authority as shown by Milgram can be counter effective in different circumstances. This occurs when people judge the expert as incredible and when people elaborate upon the arguments presented by the expert. These types of findings can be well explained by the so-called dual processing models of attitude change (Petty and Cacioppo 1986; Petty and Wegener 1999). These models in general explain why a certain persuasive cue or "trick" does not have the straightforward effect one would suggest in every possible situation. This section discusses one of the most dominant of dual processing models; the Elaboration Likelihood Model (Petty and Cacioppo 1986). This model is an exemplar for the reasoning behind most dual-processing models and provides a strong argument for situational and context awareness as well as individual adaptivity of persuasive systems.

The main notion of the ELM is the elaboration likelihood continuum; the extent to which people engage in elaborate contemplation of a persuasive message. This continuum has two end-points, given by the two routes to attitude change. First is the central route to persuasion, the route in which the actual content of the persuasive message is elaborately contemplated. The second route is the peripheral route to persuasion, in which the content is less important in the decision, but peripheral cues and mental shortcuts, such as identification with the message source or the use of heuristics, guides the resulting attitude shift.

By no means do the authors of most dual processing models propose that either one of the routes will be chosen, disregarding the other. However, authors argue that the two routes are the endpoints of the elaboration continuum. The position of an individual receiver on this continuum is determined by a number of factors, all of which are important to incorporate into fully context and situational aware adaptive persuasive systems. For the ELM Petty and Cacioppo consider the motivation to process the request, the ability to process the request, and individual prior attitudes regarding the request. Several other authors have added individual differences in need for cognition (Cacioppo et al. 1983, 1984), and/or susceptibility to persuasion (Kaptein et al. 2009), as important additional factors. In a high elaboration scenario persuasive requests that are rational and credible increase compliance. In a low elaboration scenario persuasive tricks and mental shortcuts, discussed in Sect. 8, are more likely to have a direct effect on compliance. In short the conclusions of the research into dual processing models are as follows:

- A persuasive request should be adapted to the current elaboration state of the receiver of the request.

- When people are motivated to scrutinize arguments they will be higher on the elaboration continuum.

- When people have the ability - capacity and opportunity - to elaborate on the request they will be higher on the elaboration continuum.

- When people hold prior believes about the topic at hand they will be higher on the elaboration continuum.

- People high in the need for cognition tend to be higher on the elaboration continuum.

- People who are susceptible to persuasive cues comply more based on mental shortcuts or source characteristics than people with lower susceptibility.

The first results presented in the list, a request should be adapted to the elaboration state of the receiver, is of importance to prevent backfiring (Tormala et al. 2006): the counter intuitive working of a persuasive trick. A sample of backfiring is the decreased compliance to an illegitimate expert. In low elaboration people generally follow the principle of authority, as stated above and mentioned by both Fogg (2003) and Cialdini (2001). However, experimental research has shown conflicting results. The impression of an illegitimate expert, discovered by elaborate scrutinizing by the receiver, decreases compliance. Thus, a number of the straightforward tricks-more are discussed in Sect. 8-might backfire when the central processing route is followed. This implies that persuasive systems should be aware of the motivation of the receiver, the ability to process information and several individual differences to determine the optimal persuasive strategy for the current user and the current situation.

Motivation of people to scrutinize the provided information depends on their mood, their prior beliefs, their opinion about the topic, and their need for cognition. More positive moods generally result in less elaboration than negative moods (Scharz et al. 1991). Also, attitudes or behaviors which are being held or performed for a longer period of time induce more elaboration when challenged. 
Finally, individual differences in need for cognition influence elaboration even when all else is equal. These factors should be taken into account by ambient persuasive systems to determine the most likely processing route and present arguments accordingly.

Finally, seemingly detached from the two processing routes, people seem to have different baseline susceptibility to persuasive cues (Kaptein et al. 2009). This again argues in favor of personalized, adaptive ambient persuasive systems.

\section{The onset of behavior}

This section discusses two major theories of the onset of behaviors based on attitudes or motivations towards a specific behavior. Our first is the discussion of the MOAmotivation, opportunity, and ability-model which is frequently used in marketing research to explain behavioral responses to advertisements (MacInnis et al. 1991; MacInnis and Jaworski 1989). The second model we discuss is the theory of reasoned action. The theory of reasoned action and planned behavior (TRA/PB) is used to explain the origins of behavior based on the initial attitude towards the behavior: the behavioral intention.

\subsection{Motivation, opportunity and ability}

The MOA, motivation, opportunity, and ability, model was introduced by MacInnis and Jaworski ( 1989) and elaborated upon by Rothschild (1999) and is primarily used to explain why a specific behavior occurs amongst competing behaviors. The basic principle of the MOA model is that the likelihood for a single behavior to be performed depends on the motivation to perform the behavior, the opportunity to perform the behavior, and the ability to perform the behavior (de Heer and Poiesz 1998). Motivation is the predisposition of the person performing the behavior towards the behavior and can in our model be linked to the attitude towards the behavior. Motivation is often split between intrinsic and extrinsic motivation (Ryan and Deci 2000). Intrinsic motivation refers to motivation to enact a behavior for its inherent satisfaction-its alignment with ones personal values or attitudes-and not for some separable external consequence (White 1959; Deci 1975). External motivation refers to motivation which is controlled by externalities that are not part of the activity or behavior they are influencing (Deci et al. 1998). The most common examples of external motivation are reward and punishment-more on this is explained in Sect. 9. Internal motivation seems to increase the likelihood of the behavior being performed (Deci 1975), and perhaps more importantly seems to lead to sustained behavior (Deci 1975).
Once a person is motivated, be it internally or externally, to perform a behavior the likelihood of enactment is depended on the opportunity - the extent to which the external environment enables the behavior-and a persons ability-the extent to which a person possesses the skills and knowledge necessary to enact. For example, even though a person is very willing to throw a brick through a window, first one needs to find the brink (opportunity) and secondly, one needs to be able to aim, control the arm muscles, and strike a hit (ability). In a brick less situation this behavior becomes unlikely even though motivation and ability might be high (Poiesz 1989).

The MOA model usefully identifies areas in which ambient persuasive technologies can influence the likelihood of occurrence of specific behaviors. Motivation can be influence by influencing attitudes or by providing rewards and punishments. Opportunity can be influenced by technologies by functioning as a tool (Fogg 2003) and making the target behavior easier to perform. Ability can also be influenced by using technologies to transfer knowledge or skills necessary to perform the target behavior. Here persuasive technologies as simulations (Fogg 2003) function to increase ability. The MOA model as such is valuable for ambient persuasive technologies and stresses the importance of controlling not only the person being persuaded but also his or her environment.

\subsection{Theory of reasoned action}

Another frequently reported upon theory of behavioral onset is the theory of reasoned action (TRA) and planned behavior (PB) by Azjen and Fishbein. While initially merely the Theory of reasoned action-behavior is a function of behavioral intention, which in itself is a function of attitudes and subjective norms (Ajzen and Fishbein 1980; Fishbein and Ajzen 1975) — the authors later added the notion of perceived behavioral control: Behavioral intention itself is a function of attitude towards the behavior, the subjective norms, and the perceived ability to control the behavior (Ajzen 1985, 1991). Meta studies have shown that indeed a medium proportion of variance in actual behavior was accounted for by behavioral intention and that indeed intention is party explained by attitudes (Sheppard et al. 1988).

This theory has mainly been used to explain behavior in a more clinical setting (Ajzen and Albarracin 2007), but usefully stresses the importance of attitudes and social norms in the onset of behavior. As such a persuasive ambient system should not merely know its user and its attitudes, but also the social environment in which the user is engaged. The addition of the perceived behavioral intention, planned behavior, focuses on users perceived ability and opportunity combination; up to what level are 
users singlehandedly able to perform the behavior. This combines both of the behavioral onset theories and as such identifies the key factors that should be taken into account by an ambient persuasive system aiming at influencing the likelihood of the onset of new behavioral responses.

\section{Mental shortcuts}

Besides the rational-central route-towards an attitude change and subsequent behavior, many attitudes are formed and corresponding behaviors are executed without conscious elaboration of the receiver. Cialdini $(2001,2004)$ refers to these types of attitudinal and behavioral reactions to persuasive cues as click-zoom reactions; a standardized reaction based on a mental shortcut which in general tends to be favorable for the performer of the behavior but can be used to persuade into different attitudes and behaviors. While generally unsuited to create sustainable behaviors or change behavioral patterns, mental shortcuts can be very effective in initiating a new behavior or temporarily changing attitudes. As such, we feel that results from this field deserved a separate mention in our ambient persuasion model. We first sum up the most frequently reported upon mental shortcuts-also referred to as persuasion principles:

- Principle of scarcity.

- Principle of consistency.

- Principle of loss aversion.

- Sunk cost principle.

- Principle of framing.

- The foot in the door principle.

- The contrast principle.

- The disrupt than reframe principle.

The principle of scarcity refers to people's general tendency to value things that are, or seem scarce (West 1975). People are inclined to buy a product when they know that it is the last one on stock (Cialdini 2001). This principle even leads people to do things they otherwise would not have done. When the local newspaper informs you that the nearby church, which you have not visited in years and was not planning to, is redecorating and will be closed for 6 months you suddenly find yourself wandering through church the next weekend. You are there because this was your last chance (Cialdini 2001). The implied scarcity of the behavior has made it more valuable, and thus rendered it more likely to be performed.

The principle of consistency refers to peoples strive to maintain consistent believes and act accordingly (Cialdini 2001). This strive has been well researched under the heading of reducing cognitive dissonance (Festinger 1957) and can be also used to explain both attitudes and behaviors. However, the principle can also be used to induce click-zoom reactions. If a person is asked to write down that he or she will stop taking the elevator and take the stairs instead they will be more inclined to do so even if they did not agree on writing it down in the first place (Deutsch and Gerard 1955). People will try to be consisted with their writing. The consistency principle as such also explains the power of commitment: people will act as they told or wrote they will. For ambient persuasive systems alerts on inconsistency can be a very powerful strategy.

The principle of loss aversion relates to the findings that people are more hurt by a loss of ten dollars, than they are relieved by a similar gain. Thus, people value losses higher than gains, and in a situation in which both are rationally equal, will choose the loss adverse option (Tversky and Kahneman 1981).

The sunk cost principle refers to people's tendency to incorporate previous decisions into a new decision, even though this is not rational economic behavior (Tversky and Kahneman 1974). People's tendency to include sunk costs in their decision making explains for example why people endlessly continue costly projects even if any chance of a gain has evaporated. This principle can be used when people's prior efforts for certain behaviors or attitudes are assessed and the tendency to continue previously costly behaviors is taken into account.

The framing principle refers to the opportunity a persuader has to reframe the request (Smith and Petty 1996). For example, the price of one pack of cigarettes is relatively low, however framing this option as the total amount of money required for a years' worth of smoking most probably leads to the attitude that smoking is expensive. An ambient persuasive system can use knowledge on framing to change attitudes and as such to likelihood of specific behaviors.

The foot in the door principle refers to peoples tendency to comply more too people they have already complied to. As such a small persuasive request, such as answering you by the door and enforcing this by putting your foot in the door, leads to greater compliance to following requests (Freedman and Fraser 1966). Relatively low effort questions can be followed by questions for which compliance is deemed less likely to improve compliance to a final request (Burger and Caldwell 2003).

The contrast principle-also called the contrast effectrefers to the fact that people make value judgments based on comparisons (Petty and Cacioppo 1981). As such a car stereo can be expensive when compared to the screen wipers, but is cheap compared to the car. Appropriate use of contrasting requests can increase compliance.

The disrupt-then-reframe principle is an extension to the framing principle and can be used to increase the acceptance of a reference frame. For example one can state that a 
product costs 5 dollars, which is cheap. In this option, especially in high elaboration, people will consciously elaborate on the frame (cheap) and determine for themselves whether the frame is valid. If deemed invalid backfiring will most probably occur. However, phrasing the sentence as: "This product is 500 dollar cents, that's 5 dollars, which is cheap" increases acceptance of the frame (Davis and Knowles 1999). The 500 dollar cent statement disrupts mental processing and thus renders acceptance of the frame more likely. Behavioral outcomes of usage of this principle are significant (Davis and Knowles 1999).

Designers will need to give thought on how to incorporate these mental shortcuts into their designs. These shortcuts are very powerful persuaders and are used by salesmen throughout the world. Application however needs to be done with care, since it can leave a feeling of "being tricked" which would greatly reduce the persuasive power of the system in the long run.

\section{Sustaining behavior}

The end point on the second axis of our model, from attitude to sustained behavior is the actual sustaining of behavior once it has been performed. The classical psychological approached to sustaining behavior is that of conditioning. Conditioning can be separated into the field of classical conditioning (Patterson and Romano 1987), relating two previously unrelated stimuli, and operant conditioning (Skinner 1976); enforcing behavior by the use of reward and punishment. For persuasive purposes the field of operant conditioning, which enables sustaining of voluntary performed behaviors, is most relevant.

Once favorable attitudes towards a behavior have been formed, and the behavior is performed for a first time, several methods of stimulating or inhibiting the behavior can be of use. Traditionally one separates reinforcements, consequences of the behavior that make the behavior more likely, and punishments, consequences that render the behavior less likely. Since both of consequences can either be removed or added, there are four possible reinforcement schemes (Ferster and Skinner 1957):

1. Positive reinforcers: A behavior is followed by a positive stimulus (reward).

2. Negative reinforcers:A behavior is followed by the removal of a negative stimulus (punishment).

3. Positive punishment: A behavior is followed by a negative stimulus.

4. Negative punishment: A behavior is followed by the removal of a positive stimulus.

All four of these schemes can be used by ambient persuasive systems to reinforce behavior. Since the notion of operant conditioning is relatively old numerous effects have been described and researched. A lot of work has been done on extinction, the effects of neither reinforcing nor punishing a behavior, after a behavior has been conditioned. Typically one observes an extinction boom: a sudden frequent outburst of the behavior. Next to extinction effects a number of different punishment and reinforcement schedules have been researched. Also, the cognitive trade-offs between a number of positive and negative reinforcers have been studied.

The literature identifies different schedules of reinforcement and their behavioral outcomes (Ferster and Skinner 1957). One can distinguish between time reinforcers or ratio reinforcers; a reward or punishment after a number of times the behavior has been performed (ratio) or a specific time after the first occurrence of the behavior (time). Both of these can be done specifically or variable, in which variable implies that the behavior is not reinforced on regular intervals.

Additional to reinforcement type and reinforcement schedule work has been done on trade offs between positive and negative reinforcers. People seem to trade of the sum of reinforcers and if the net reinforcement value is positive the behavior will increase, while it will decrease if the net reinforcement value is low.

A final notion useful from the conditioning literature is the concept of shaping: Adapting reinforcers to more and more specific instances of behavior. For example, one is first rewarded for hitting a button, and then only rewarded for hitting a button twice in a timed sequence. Based on this numerous types of behaviors can be shaped and sustained.

The knowledge on conditioning can proof useful for sustaining compliance behavior to ambient persuasive technologies. After a behavior has occurred reinforcement or punishment can be used to sustain the behavior. Currently, game design is an area in which conditioning principles are used to sustain behavior (Bang et al. 2006).

\section{Future challenges}

We presented an elaborate model of persuasion, emphasizing the complex base of attitudes and behavioral change. All of our persuasion principles are summarized in Table 1. Far more than computer based or "boxed" persuasive technologies would ambient technologies be capable of capturing and incorporating in their persuasive actions these complex principles of attitude and behavioral change.

Ambient persuasive systems offer an opportunity to incorporate a user model of persuasion, situational and context awareness, and timely delivery of messages. Thus, 
Table 1 A summary of all the persuasion principles derived from the ambient persuasion model

\begin{tabular}{|c|c|c|}
\hline Model concept & Persuasion principle & Explanation \\
\hline \multirow[t]{6}{*}{ Source } & Authority & People are more likely to comply to a request made be a legitimate authority \\
\hline & Liking & $\begin{array}{l}\text { People are more likely to comply to a request made by their friends and people } \\
\text { they like }\end{array}$ \\
\hline & Similarity & $\begin{array}{l}\text { People are more likely to comply to people similar (i.e. age, name, background, } \\
\text { interest) to themselves }\end{array}$ \\
\hline & Mimicry & $\begin{array}{l}\text { People are more likely to comply to a request when their own behavior or } \\
\text { phrasing is mimicked by the persuader }\end{array}$ \\
\hline & Reciprocation & People are inclined to return a favor \\
\hline & Repetition & Repetition of a persuasive request increases compliance \\
\hline \multirow[t]{4}{*}{ Multiple source } & Social proof & $\begin{array}{l}\text { People-primarily in unfamiliar situations-look at others to see what they } \\
\text { should do }\end{array}$ \\
\hline & Number of people & $\begin{array}{l}\text { People are more inclined to adopt a behavior or attitude when it is expressed by a } \\
\text { bigger group of sources }\end{array}$ \\
\hline & Immediacy & $\begin{array}{l}\text { Compliance is a trade off of the number of people, and the closeness of these } \\
\text { people to the persuade }\end{array}$ \\
\hline & Consensus & $\begin{array}{l}\text { People seek consensus. Even in familiar situations people want to agree with the } \\
\text { majority view }\end{array}$ \\
\hline \multirow[t]{4}{*}{ Attitudes } & Mental accessibility & Attitudes that are easily accessible are stronger than those that are hard to recall \\
\hline & Ambivalence & $\begin{array}{l}\text { Attitudes based on consistent information are more difficult to change than those } \\
\text { based on conflicting arguments }\end{array}$ \\
\hline & Mood & $\begin{array}{l}\text { Attitudes with an affective base are hard to change with cognitive arguments and } \\
\text { vice versa }\end{array}$ \\
\hline & Individual differences & Individuals differ in their initial attitudes towards objects \\
\hline \multirow[t]{6}{*}{ Information processing } & High elaboration & $\begin{array}{l}\text { People who are high on the elaboration continuum-follow the central route to } \\
\text { persuasion- are inclined to listen to rational arguments }\end{array}$ \\
\hline & Low elaboration & $\begin{array}{l}\text { People who are low on the elaboration continuum- follow the peripheral route } \\
\text { to persuasion-are susceptible to peripheral cues and persuasive tricks }\end{array}$ \\
\hline & Ability to elaborate & $\begin{array}{l}\text { People differ in their ability to elaborate, and thus in their initial position on the } \\
\text { elaboration continuum }\end{array}$ \\
\hline & Prior believes & Prior believes about a topic will raise the elaboration position of people \\
\hline & Need for cognition & $\begin{array}{l}\text { People high in the need for cognition will be higher on the elaboration } \\
\text { continuum }\end{array}$ \\
\hline & Susceptibility to cues & $\begin{array}{l}\text { People who are more susceptible to persuasive cues will be lower on the } \\
\text { elaboration continuum }\end{array}$ \\
\hline \multirow[t]{4}{*}{ Behavior } & Motivation & $\begin{array}{l}\text { Behavior will only be displayed when an individual is motivated (intrinsically or } \\
\text { extrinsically) to perform the behavior }\end{array}$ \\
\hline & Opportunity & $\begin{array}{l}\text { Behavior can only be displayed when the environment offers the opportunity to } \\
\text { perform the behavior }\end{array}$ \\
\hline & Ability & $\begin{array}{l}\text { Behavior can only be displayed when an individual has the ability to carry out } \\
\text { the behavior }\end{array}$ \\
\hline & Reasoned action & $\begin{array}{l}\text { Behavior is based on peoples initial attitude towards the behavior, and the } \\
\text { estimated chances of being able to perform the behavior }\end{array}$ \\
\hline \multirow[t]{8}{*}{ Mental shortcuts } & Scarcity & People value objects that are scarce \\
\hline & Consistency & People seek consistency in their own behaviors and attitudes \\
\hline & Loss aversion & People are loss averse and will excel effort to prevent possible loss \\
\hline & Sunk costs & People incorporate previous decisions in new decisions \\
\hline & Foot in the door & People will comply to a series of small request more easily than to a big request \\
\hline & Framing & $\begin{array}{l}\text { The persuader has the opportunity to frame a request in a way consistent with the } \\
\text { request }\end{array}$ \\
\hline & Contrasting & $\begin{array}{l}\text { People make decisions based on comparisons. The persuader can provide the } \\
\text { comparison }\end{array}$ \\
\hline & Disrupt than reframe & People are more susceptible to frames when their processing is disrupted \\
\hline
\end{tabular}


Table 1 continued

\begin{tabular}{lll}
\hline Model concept & Persuasion principle & Explanation \\
\hline Sustaining & Positive reinforcers & Reward will stimulate the continuation of behavior \\
& Negative reinforcers & Removal of punishments will stimulate the continuation of behavior \\
& Positive punishment & Punishment will inhibit the continuation of behavior \\
& Negative punishment & Removal of rewards will inhibit the continuation of behavior \\
\hline
\end{tabular}

ambient persuasive systems can reach a greater overall compliance. Based on the model described above, which summarizes parts of the work on attitude and behavioral change as found in social sciences, we identify the key aspects which are opportunities not just for persuasive technologies in general, but more specifically for ambient persuasive technologies. The challenge for the field in the years to come will be to prove its efficiency on these key indicators-indeed reaching higher compliance because of the specific opportunities-and as such ground the need for the ambient approach in truly persuasive systems. We identify the following three challenges in which ambient persuasive technologies can outwit their boxed counterparts:

1. Ambient persuasive technologies could be context and situation aware.

2. Ambient persuasive technologies can adapt to individual differences.

3. Ambient persuasive technologies can function as actors themselves.

The vertical axis in our model clearly showed different persuasion strategies to be effective in different stages of the attitude-behavior continuum. Furthermore, trade offs between behaviors, such as suggested by the MOA model, and ambivalence of attitudes emphasizes the importance of delivering the right message-tailored towards the current stage of the model-in the right context. Since persuasive technologies can incorporate a multitude of sensing methods to determine context and situation they should be better suited than traditional persuasive technologies to incorporate these into their persuasive efforts and as such become more effective.

As is clear from numerous accounts in this article, strategies adapted to individual users are most promising for increasing compliance in the ambient persuasion scenario. Individuals differ in their tendency towards central or peripheral information processing, and individuals differ in their initial motivation and ability. For ambient persuasive systems to be truly effective and ensure compliance these individual differences should influence the strategies adapted by the system. By having access to numerous aspects of the individual persuasive systems should be more efficient in creating a user model of susceptibility to persuasion. As such, the ambient persuasive system has a greater opportunity to tailor its persuasive actions towards the specific user.

Finally, based on the horizontal axes of our model-the source receiver model-it is clear that source characteristics play an important role in persuasion. While technologies can facilitate the connection of human sources, ambient systems could also be a social actor by themselves. Reeves and Nass (1996) showed already that even computers are interpreted as social actors. Persuasive systems could embody this actor role more diversely and convincingly than their "boxed" counterparts since they could utilize a multitude of system representations, tailored for the specific occasion and context. The ambient persuasive system as an actor needs not only functional intelligence but also social intelligence to be able to form a bond with the receiver-one of the source characteristics which increases its persuasive power.

\section{Conclusion}

This article presented the role ambient persuasive technologies can have in our everyday life: shaping attitudes and behavior. We argued that, more than boxed persuasive technologies, ambient persuasive technologies can leverage situational awareness, context awareness, and user awareness to increase the efficiency. To leverage these opportunities we provided a more detailed view on the knowledge of attitude and behavioral change than that provided by those only discussing tricks or persuasion principles. By structuring the knowledge around a 2-axis model we hope to have provided a structure to system designers to incorporate this knowledge in their designs.

The future challenges pose a number of testable hypothesis for the development of persuasive AmI systems. These hypothesis are derived from our structuring of the social science knowledge, but still need to be proven in an AmI scenario. We present the three main hypothesis:

1. The compliance to requests from an ambient persuasion system can be increased by incorporating contextual or situational knowledge. Persuasive AmI systems which utilize this knowledge will be more effective 
than systems which do not utilize this data. Truly contextual and situational awareness of systems is only made possible by the AmI paradigm and as such the time has arrived to test this hypothesis.

2. Compliance to persuasive requests is increased when requests are tailored to the individual. This effect should be larger than the individual main effects of persuasive cues or strategies. It is hypothesized that different combinations of cues, in different situations, for different individuals lead to the highest compliance rates.

3. Compliance to a persuasive request is enhanced when done by a socially smart system which is regarded a social actor as compared to an actorless system. Imposing social structures-complex ones like personality, or simple ones like merely naming a system-should increase compliance over systems which elicit less of a social response.

The three hypotheses mentioned here can easily be tested using psychological experimental methods. Such test will serve to show that while theoretically sensible based on previous human to human research, the aforementioned challenges are indeed worth a follow up. If the psychological effects of these assumptions have been shown, implications for technological development and an ethical discussion should follow.

In the future ambient persuasion should aim at delivering on its promises. Both experimental research as well as field trials should confidently proof the added value of the ambient paradigm on top of the already booming field of persuasive technologies.

Acknowledgments We would like to acknowlege Joris H. Janssen for his valuable comments and insights.

Open Access This article is distributed under the terms of the Creative Commons Attribution Noncommercial License which permits any noncommercial use, distribution, and reproduction in any medium, provided the original author(s) and source are credited.

\section{References}

Aarts EHL, Ruyter BER (2009) New research perspectives on ambient intelligence. J Ambient Intell Smart Environ 1:5-14

Aarts EHL, Markopoulos P, de Ruyter BER (2007) The persuasiveness of ambient intelligence. In: Petkovic M, Jonker W (eds) Security, privacy and trust in modern data management. Springer, Berlin

Ajzen I, Albarracin D (2007) Predicting and changing behavior: a reasoned action approach. In: Fishbein M, Ajzen I, Albarracin D, Hornik R (eds) Prediction and change of health behavior. Routledge, London

Ajzen I (1985) From intentions to actions: a theory of planned behavior. In: Kuhl J, Beckmann J (eds) Action-control: from cognition to behavior. Springer, Heidelberg, pp 1 1-39
Ajzen I (1991) The theory of planned behavior. Organ Behav Hum Decis Process 50:179-211

Ajzen I, Fishbein M (1980) Understanding attitudes and predicting social behavior. Prentice-Hall, Englewood Cliffs

Asch SE (1955) Opinions and social pressure. Sci Am 193:31-35

Bang M, Torstensson C, Katzeff C (2006) The powerHouse: a persuasive computer game designed to raise awareness of domestic energy consumption. In: IJsselsteijn WA, de Kort YAW, Midden CJH, Eggen JH, van den Hoven EAWH (eds) PERSUASIVE 2006. LNCS, 3962, Springer Verlag, New York, pp 123-132

Bargh JA, Chaiken S, Raymond P, Hymes C (1996) The automatic evaluation effect: unconditional automatic attitude activation with a pronunciation task. J Exp Soc Psychol 32:104-128

Breckler SJ (1994) A comparison of numerical indexes for measuring attitude ambivalence. Educational Psychol Meas 54:350-365

Burger JM, Caldwell DF (2003) The effects of monetary incentives and labeling on the foot-in-the-door-effect. Basic Appl Soc Psychol 25:235-241

Burger JM, Messian N, Shebani P, del Prado A, Anderson C (2004) What a coincidence! The effects of incidental similarity on compliance. Pers Soc Psychol Bull 30:35-43

Cacioppo JT, Berntson GG (1994) Relationship between attitudes and evaluative space: a critical review, with emphasis on the separability of positive and negative substrates. Psychol Bull 115:401-423

Cacioppo JT, Petty RE, Kao CF (1984) The efficient assessment of need for cognition. J Pers Assess 48:306-307

Cacioppo JT, Petty RE, Morris KJ (1983) Effects of need for cognition on message evaluation, recall, and persuasion. J Pers Soc Psychol 45:805-818

Chartrand TL, Bargh JA (1999) The Chameleon effect: the perception-behavior link and social interaction. J Pers Soc Psychol 76:893-910

Chartrand TL, Maddux WW, Lakin JL (2005) Beyond the perceptionbehavior link: The ubiquitous utility and motivational moderators of nonconscious mimicry. In: Hassin R, Uleman J, Bargh JA (eds) Unintended thought 2: the new unconscious. Oxford University Press, New York

Cialdini R (2001) Influence, science and practice. Allyn and Bacon, Boston

Cialdini R (2004) The science of persuasion. Sci Am Mind 284:76-81

Cialdini RB, Goldstein NJ (2004) Social influence: compliance and conformity. Annu Rev Psychol 55:591-622

Davis BP, Knowles ES (1999) A dirupt-then-reframe technique of social influence. J Pers Soc Psychol 76:192-199

de Heer J, Poiesz T (1998) Dynamic characteristics of motivation, ability and opportunity to process commercial information. Adv Consumer Res 25:532-537

Deci EL (1975) Intrinsic motivation. Plenum, New York

Deci EL, Koestner R, Ryan RM (1998) Extrinsic rewards and intrinsic motivation: clear and reliable effects. Unpublished manuscript, University of Rochester

Deutsch M, Gerard HB (1955) A study of normative and informational social influences upon individual judgment. J Abnorm Soc Psychol 51:629-636

Fazio RH (1993) Variability in the likelihood of automatic attitude activation: data reanalysis and commentary on Bargh, Chaiken, Govender, and Pratto. J Pers Soc Psychol 64:753-758

Fazio RH (1995) Attitudes as object-evaluation associations: determinants, consequences, and correlates of attitude accessibility. See Petty and Krosnick 1995. pp 247-282

Ferster CB, Skinner BF (1957) Schedules of reinforcement. American Psychological Association, Washington

Festinger L (1954) A theory of social comparison processes. Hum Relat 7:117-140 
Festinger L (1957) A theory of cognitive dissonance. Stanford University Press, Stanford

Fishbein M, Ajzen I (1975) Belief, attitude, intention, and behavior: an introduction to theory and research. Addison-Wesley, Reading

Fogg BJ (2003) Persuasive technology: using computers to change what we think and do. Morgan Kaufmann, Menlo Park

Freedman JL, Fraser SC (1966) Compliance without pressure: the foot in the door technique. J Pers Soc Psychol 4:195-203

James JM, Bolstein R (1992) Effect of monetary incentives and follow-up mailings on the response rate and response quality in mail surveys. Public Opin Q 54:442-453

Kaptein MC, Markopoulos P, de Ruyter B, Aarts E (2009) Simple ways to make friends. Proceedings of the 8th international workshop on social intelligence design, Kyoto, Japan

Kaptein MC, Markopoulos P, de Ruyter B, Aarts E (2009) Can you be persuaded? Individual differences in susceptibility to persuasion. Proceedings of interact 2009, Uppsala, Sweden. LNCS, Springer

Komorita SS, Hilgy JA, Parks CD (1991) Reciprocity and cooperation in social dilemmas. J Confl Resolut 35:494-518

Latane B, Bourgeois MJ (1996) Experimental evidence for dynamic social impace: the emergence of subcultures in electronic groups. J Commun 46:35-47

Latane B, Liu JH, Nowak A, Bonevento M, Zheng L (1995) Distance matters: physical space and social impact. Pers Soc Psychol Bull 21:795-805

Latane B, Darley J (1968) The unresponsive bystander: why doesn't he help? Appleton (Century/Crofts), New York

Latane B, Nida S (1981) Ten years of research on group size and helping. Psychol Bull 89:308-324

Latane B (1996) Dynamic social impact: the creation of culture by communication. J Commun 46:13-25

Leippe MR, Eisenstadt D (1994) Generalization of dissonance reduction: decreasing prejudice through induced compliance. J Pers Soc Psychol 67:395-413

Lykken DT, Bouchard TJ, McGue M, Tellegen A (1993) Heritability of interests: a twin study. J Appl Psychol 78:649-661

MacInnis DJ, Jaworski BJ (1989) Information processing from advertisements: toward an Integrative framework. J Mark 53:1-23

MacInnis DJ, Moorman C, Jaworski BJ (1991) Enhancing and measuring consumers motivation, opportunity, and ability to process brand information from ads. J Mark 55:32-53

Milgram S (1963) Behavioral study of obedience. J Pers Soc Psychol $52: 500-510$

Milgram S (1974) Obedience to authority. Tavistock, London

Millers AG, Collins DT, Brief DE (1995) Perspectives on obedience to authority: the legacy of the Milrgam experiments. J Soc Issues 51(3): $1-20$

Murray DA, Leupker EV, Johnson CA, Mittlemark MB (1984) The prevention of cigarette smoking in children: a comparison of four strategies. J Appl Soc Psychol 14:274-288

Nass C, Moon Y (2000) Machines and mindlessness: social responses to computers. J Soc Issues 56:81-103

Nowak A, Szamrej J, Latane B (1990) From private attitude to public opinion: a dynamic theory of social impact. Psychol Bull 97:362-376

Olson JM, Zanna MP (1993) Attitudes and attitude change. Annu Rev Psychol 44:117-154

O'Keefe DJ (2002) Persuasion: theory and research. Sage, Beverly Hills

Patterson MM, Romano AG (1987) The rabbit in Pavlovian conditioning. In: Gormezano I, Prokasy WF, Thompson RF (eds) Classical conditioning. Lawrence Erlbaum Associates, New Jersey

Petty RE, Cacioppo JT (1986) The elaboration likelihood model of persuasion. In: Berkowitz L (ed) Advances in experimental social psychology, vol 19. Academic Press, New York, pp 123 205

Petty RE, Cacioppo JT (1981) Attitudes and persuasion: classic and contemporary approaches. W.C. Brown, Dubuque

Petty RE, Wegener DT (1999) The elaboration likelihood model: current status and controversies. In: Chaiken S, Trope Y (eds) Dual-process theories in social psychology. Guilford Press, New York

Petty RE, Priester JR, Wegener DT (1994) Cognitive processes in attitude change. In: Wyer RS, Srull TK (eds) Handbook of social cognition, 2nd edn. Erlbaum, Hillsdale 2:69-142

Petty RE, Wegener DT, Fabrigar LR (1997) Attitudes and attitude change. Annu Rev Psychol 48:609-647

Pinel EC, Long AE, Landau MJ, Alexander K, Pyszczynski T (2006) Seeing I to I: a pathway to interpersonal connectedness. J Pers Social Psychol 90:243-257

Poiesz TBC (1989) De transformatie van een karikatuur over de ontwikkeling van het consumentenbeeld in de psychologie van de reclame, Inaugurale rede, Katholieke Universiteit Brabant

Poiesz T, Robben HS (1996) Advertising effects under different combinations of motivation, capacity, and opportunity to process Information. Adv Consumer Res 23:231-236

Reeves B, Nass C (1996) The media equation: how people treat computers, television, and new media like real people and places. Cambridge University Press, Cambridge

Rothschild M (1999) Carrots, sticks, and promises: a conceptual framework for the management of public health and social issues behavior. J Mark 63:24-37

Ryan RM, Deci EL (2000) Intrinsic and extrinsic motivations: classic definitions and new directions. Contemp Educational Psychol 25:54-67

Scharz N, Bless H, Bohner G (1991) Mood and persuasion: Affective states influence the processing of persuasive communications. In: Zanna MP (ed) Advances in experimental social psychology. Academic Press, London

Sheppard BH, Hartwick J, Warshaw PR (1988) The theory of reasoned action: a meta-analysis of past research with recommendations for modifications and future research. J Consumer Res 15:325-343

Shultz PW (1999) Changing behavior with normative feedback interventions: a field experiment on curbside recycling. Basic Appl Psychol 21:25-36

Skinner BF (1976) About behaviorism. Vintage Books, New York

Slater M, Altley A, Davison A, Swapp D, Guger C, Barker C, Pistrang N, Sanchez-Vives MV (2006) A virtual reprise of the Stanley milgram obedience experiments. PLoS ONE 1(1):e39. doi: 10.1371/journal.pone.0000039

Smith SM, Petty RE (1996) Message framing and persuasion: a message processing analysis. Pers Soc Psychol Bull 22:257-268

Tesser A (1993) The importance of heritability in psychological research: the case of attitudes. Psychol Rev 100:129-142

Thompson MM, Zanna MP, Griffin DW (1995) Lets not be indifferent about (attitudinal) ambivalence. See Petty \& Krosnick 1995, pp 361-86

Tormala ZL, Brinol P, Petty RE (2006) J Exp Soc Psychol 42:684691

Tversky A, Kahneman D (1974) Judgement under uncertainty: heuristics and biases. Science 185:1124-1131

Tversky A, Kahneman D (1981) The framing of decisions and the psychology of choice. Science 211:453-458

Tybout AM, Sternthal B, Malaviya P, Bakamitsos GA, Park S (2005) Ease of information accessibility as a moderator of judgments: the role of content versus retrieval. J Consumer Res 32:76-85

West SG (1975) Increaing the attractiveness of college cafetaria food: a reactance theory perspective. J Appl Psychol 60:656-658

White RW (1959) Motivation reconsidered. Psychol Rev 66:297-333 